\title{
Feeding by the zooflagellate Pseudobodo sp. on the picoplanktonic prasinomonad Micromonas pusilla*
}

\author{
J. S. Parslow ${ }^{1 *}$, G. J. Doucette ${ }^{2}$, F. J. R. Taylor ${ }^{1,2}$ \& P. J. Harrison ${ }^{1,2}$ \\ ${ }^{1}$ Department of Oceanography, University of British Columbia, Vancouver, British Columbia V6T 1W5, Canada \\ ${ }^{2}$ Department of Botany, University of British Columbia, Vancouver, British Columbia V6T 2Bl, Canada
}

\begin{abstract}
The trophodynamic interaction between a heterotrophic zooflagellate, Pseudobodo sp. ( 2 to $4 \mu \mathrm{m}$ ) and a small $(-2 \mu \mathrm{m})$ prasinophyte, Micromonas pusilla, was studied in continuous culture. This zooflagellate was capable of phagocytizing Micromonas and causing a rapid decline in cell numbers of the latter. Maximum growth rate of the zooflagellate was about $2 \mathrm{~d}^{-1}$ and maximum clearance rate was about $1 \times 10^{-8} 1 \mathrm{ind}^{-1} \mathrm{~d}^{-1}$. A video system was used to record its feeding behaviour. We attempted to estimate population parameters by deliberately perturbing the experimental system and using systems identification procedures to fit non-linear dynamic models to the resulting time series. Our results suggest that the response of zooflagellates to fluctuating food densities is intrinsically more complicated than observations of steady-state growth would suggest. These complexities include both time lags in the response of ingestion to increasing food density, and a complex response of cell size, physiological state and depth rate to decreasing food density. Present observations suggest that considerable caution should be exercised in the use of steady-state chemostat results to predict or model zooflagellate populations in the field.
\end{abstract}

\section{INTRODUCTION}

With the development of new techniques for the enumeration and identification of nanoplankton, their role in marine food webs has assumed increasing significance. Epifluorescence and electron microscope studies have shown that picoplankton (cyanobacteria and eukaryotes on the order of $1 \mu \mathrm{m}$ diameter) comprise a large fraction of the autotrophic biomass and production in some regions (Johnson \& Sieburth 1979, 1982, Davis \& Sieburth 1982).

Other studies have shown heterotrophic bacterial biomass and production to be greater than previously believed; 10 to $50 \%$ of the carbon fixed by photosynthesis may pass through bacteria (for reviews, see Sorokin 1981, Azam et al. 1983). The primary consumers in these food webs may also be very small. There is

\footnotetext{
- This paper is dedicated to Dr. N. J. Antia on the occasion of his retirement to acknowledge his important contributions to phycology and algal physiology

- Present address: School of Australian Environmental Studies, Griffith University Nathan, Queensland 4111, Australia
}

now considerable direct and indirect evidence for the importance of heterotrophic microflagellates, in the size range 3 to $8 \mu \mathrm{m}$, as consumers of bacteria in natural systems (Caron et al. 1982, Fenchel 1982d, Johnson et al. 1982, Sieburth \& Davis 1982, Azam et al. 1983, Sherr \& Sherr 1983, Davis \& Sieburth 1984, Sherr et al. 1984).

A number of key laboratory studies have contributed to our understanding of the bacteria-microflagellate interaction. Several species of microflagellates have been successfully grown in laboratory culture on bacteria, and their growth rates, clearance rates, assimilation efficiencies and ammonia excretion rates quantified (Fenchel 1982a, b, Sherr et al. 1983). Heterotrophic microflagellates have higher clearance rates than larger microzooplankton for particles in the size range of bacteria and seem more likely to be an effective controlling agent at natural densities. It seems plausible that these flagellates are also important consumers of autotrophic picoplankton. One field study has reported their consumption of cyanobacteria (Johnson et al. 1982), but laboratory studies examining this type of interaction have not been reported to date. Our paper presents an analysis of the interaction 


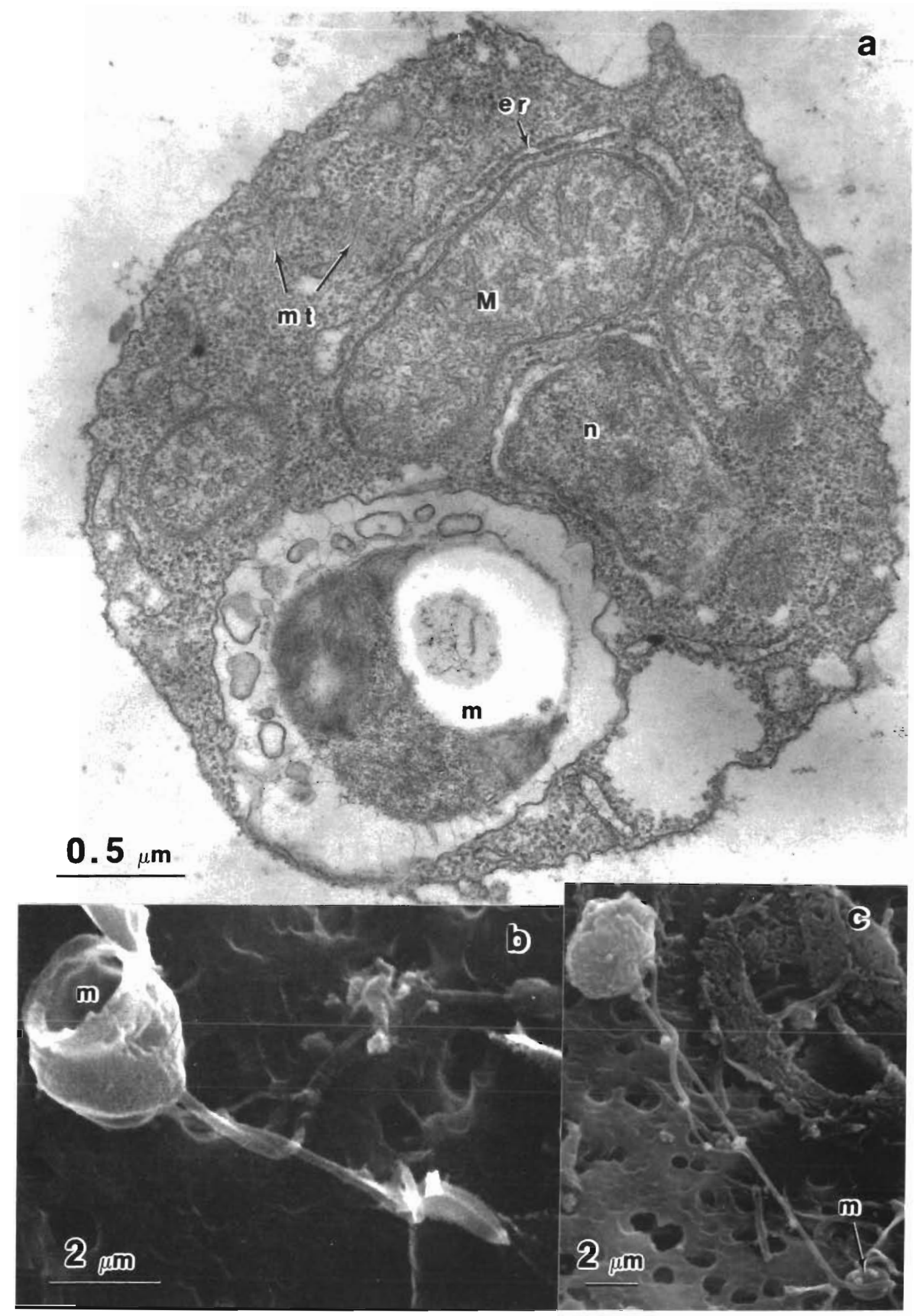

Fig. 1. Pseudobodosp. (a) TEM section containing recently ingested Micromonas pusilla cell (m). Note presence of microtubules (mt) possibly comprising cytostome. Other organelles, including nucleus (n) mitochondria (M) and rough endoplasmic reticulum (er) are also apparent. (b) SEM of Pseudobodosp. ingesting M. pusilla cell (m). Cytostome dilated to greater than twice its normal diameter (c) SEM of Pseudobodo sp. showing 2 laterally inserted flagella of different length. Extended longer flagellum lying over $M$. pusilla cell (m) 
between a heterotrophic zooflagellate, Pseudobodosp. (2 to $4 \mu \mathrm{m}$ ), and a small (1 to $2 \mu \mathrm{m}$ ) prasinophyte, Micromonas pusilla, in continuous laboratory culture.

\section{MATERIALS AND METHODS}

The isolate of Micromonas pusilla used in this study was obtained from the Northeast Pacific Culture Collection (clone 29-1) and was originally isolated from the Strait of Georgia, British Columbia, Canada. It was grown in continuous culture on an artificial seawater medium (ESAW: Harrison et al. 1980) with the modifications described in Parslow et al. (1984). Ammonium chloride $(50 \mu \mathrm{M})$ was the sole nitrogen source in the inflow medium. The culture was maintained at $18^{\circ} \mathrm{C}$ under an incident irradiance of $80 \mu \mathrm{Ein} \mathrm{m}^{-2} \mathrm{~s}^{-1}$. The culture vessel was a $2 \mathrm{l}$ boiling flask, sealed by a silicon stopper, with an inlet port for medium and outlet ports for overflow and sampling. The culture was stirred at $60 \mathrm{rpm}$ by a Teflon-coated magnetic stir bar. A piston pump (Fluid Metering Inc., New Jersey) was set so as to dilute the culture with sterile medium at a constant rate of $0.75 \mathrm{~d}^{-1}$.

The heterotrophic zooflagellate Pseudobodo sp. appeared in a Micromonas pusilla culture as a laboratory derived contaminant. When it first appeared Pseudobodo caused a precipitous decline in the density of $M$. pusilla. In order to study the dynamics of this interaction further, we arranged a series of fluctuations in the density of the 2 species by turning the dilution pump on and off at intervals of several days. These intervals were chosen so as to prevent $M$. pusilla densities from becoming large enough to deplete ambient ammonium. (Consequently we were able to study the predator-prey interaction without the added complexities of nitrogen limitation.) The pump intervals were also chosen so as to produce a range of peak $M$. pusilla densities, and to prevent $M$. pusilla densities from dropping so low as to result in inordinate delays between cycles.

Samples were withdrawn by syringe once or twice per day for monitoring of in vivo fluorescence and particle-size distributions using a Coulter-Counter Model TAII. The feeding behaviour of Pseudobodo sp. was studied under the light microscope at $400 \times$ and encounters were recorded on videotape.

Aliquots of culture containing the highest densities of Pseudobodo sp. were prepared for scanning (SEM) and transmission (TEM) electron microscopy by initially collecting cells on either a $1.0 \mu \mathrm{m}$ polycarbonate Nuclepore filter (SEM) or a $0.45 \mu \mathrm{m}$ Type HA Millipore filter (TEM), fixing with $1.5 \%$ glutaraldehyde in $0.1 \mathrm{M}$ sodium cacodylate and $0.4 \mathrm{M}$ sucrose $(1.5 \mathrm{~h}$, room temp.), and postfixing with $1 \%$ osmium tetroxide in
$0.1 \mathrm{M}$ sodium cacodylate ( $1 \mathrm{~h}$, room temp.). At this point samples for SEM were dehydrated in a graded ethanol series, critical point dried, coated with platinum, and examined under a Cambridge Stereoscan 250T scanning electron microscope. Following postfixation specimens for TEM were en bloc stained with $1 \%$ aqueous uranyl acetate, dehydrated in an ethanol/ propylene oxide series, and embedded in Epon 812. Silver sections cut using a diamond knife were stained with saturated uranyl acetate (in $70 \%$ ethanol) and lead citrate, and examined using a Zeiss EM10 transmission electron microscope.

\section{RESULTS AND ANALYSIS}

\section{Zooflagellate taxonomy}

The zooflagellate in our study most closely resembles Pseudobodo tremulans Griessmann (1914) but differs in being smaller (body length 2 to $4 \mu \mathrm{m}$ versus 5 to $7 \mu \mathrm{m})$, not flattened like Griessmann's species, and possessing a cytostome in a fixed location on the surface, antero-dorsal to the laterally inserted flagella (Fig. 1a, b). Like $P$. tremulans it can swim freely or attach itself by the posterior flagellum (Fig. 2a). The anterior flagellum of our organism is smooth (Fig. 1b, c) lacking the hairs found on flagella of chrysomonads and other heterokont phytoflagellate groups. The body shape of the zooflagellate in the present study can be altered considerably by ingestion of Micromonas pusilla (up to 3 per cell seen) with resulting food vacuoles clearly visible at both the light and electron microscope levels (Fig. 1a). A contractile vacuole is lacking.

Fenchel (1982a) investigated the feeding of an organism he described as Pseudobodo tremulans. However, these cells possessed a single row of mastigonemes on the anterior flagellum and a prominent lip
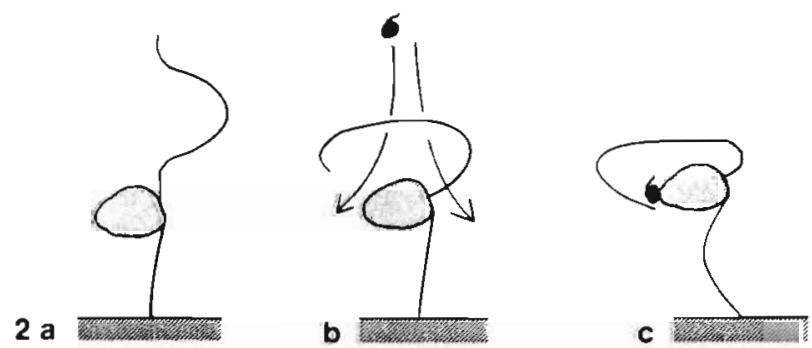

Fig. 2. (a) Schematic representation of Pseudobodo sp. attached to substrate and showing normal position of flagella. (b) Schematic demonstrating movement of Micromonas pusilla cell toward Pseudobodosp. caused by current induced by anterior flagellum. (c) $M$. pusilla cell struck to cytostome by anterior flagellum 
on a cytostome located at the base of this flagellum. The smooth posterior flagellum runs through a ventral groove. The $P$. tremulans of Fenchel is clearly different from that which we have observed (e.g. lack of mastigonemes and location of cytostome). Except for a small disparity in size our zooflagellate, rather than Fenchel's, appears more similar to that described by Griessmann (1914). Clearly, either Fenchel's or our organism must be classed as a genus other than Pseudobodo; however, as Griessmann makes no reference to a cytostome (flageller hairs would probably not have been discernible) we cannot be sure which should be retained as Pseudobodo sp. and are preparing a taxonomic description for later publication.

\section{Feeding behaviour}

When observed under the light microscope Pseudobodo sp. tended to attach to the glass slide with the posterior flagellum (Fig. 2a), and beat the anterior flagellum so as to maintain a current of water towards its body. The beating of the anterior flagellum during feeding is so rapid that it appears static and held in an arched position over the anterior of the cell. Particles are drawn in a flow normal to the curve of the flagelIum (Fig. 2b). Micromonas pusilla cells which swam or drifted near a Pseudobodo were observed to suddenly accelerate (from a distance of ca $15 \mu \mathrm{m}$ ) towards the zooflagellate. There appeared to be a critical period in which an $M$. pusilla cell was either captured at the zooflagellate surface (Fig. 2c) or escaped. Capture success was relatively low in our experience. At the light microscope level we were unable to tell whether ingestion occurred at a specialized site or cytostome. However, electron micrographs (Fig. 1a, b) provide evidence of a fixed hollow in the Pseudobodo surface which may be used for this purpose. The general feeding technique is basically similar to that described previously for Pseudobodo tremulans and Pleuromonas jaculans (Fenchel 1982a).

\section{Population data and analysis}

The Coulter-Counter data for the 52 d duration of the study (Fig. 3) show 6 coupled predator-prey cycles. The Micromonas pusilla and Pseudobodo sp. distributions are almost completely separated in these data on the basis of size, with $M$. pusilla occurring in channels 3, 4, and 5 (1.3 to $2.6 \mu \mathrm{m}$ dia.), and Pseudobodo in channels 6 to $9(2.6$ to $6.4 \mu \mathrm{m}$ dia.). There is a very slight spillover of $M$. pusilla into channel 6 . The size-frequency data were converted to biomass (total cell volume in $\mu \mathrm{m}^{3} \mathrm{1}^{-1}$ ) by multiplying numbers in each chanhel by the mean particle volume for that channel, and summing over the channels appropriate to each species. The $M$. pusilla counts in channel 6 were estimated to be $4 \%$ of the counts in channel 5 and this proportion was allowed for in the biomass calculations for both species. The results (Fig. 4) show that peak biomass levels were comparable for the 2 species. There was a tight linear relation between the biomass estimates for M. pusilla and the in vivo fluorescence measurements made at the same time.

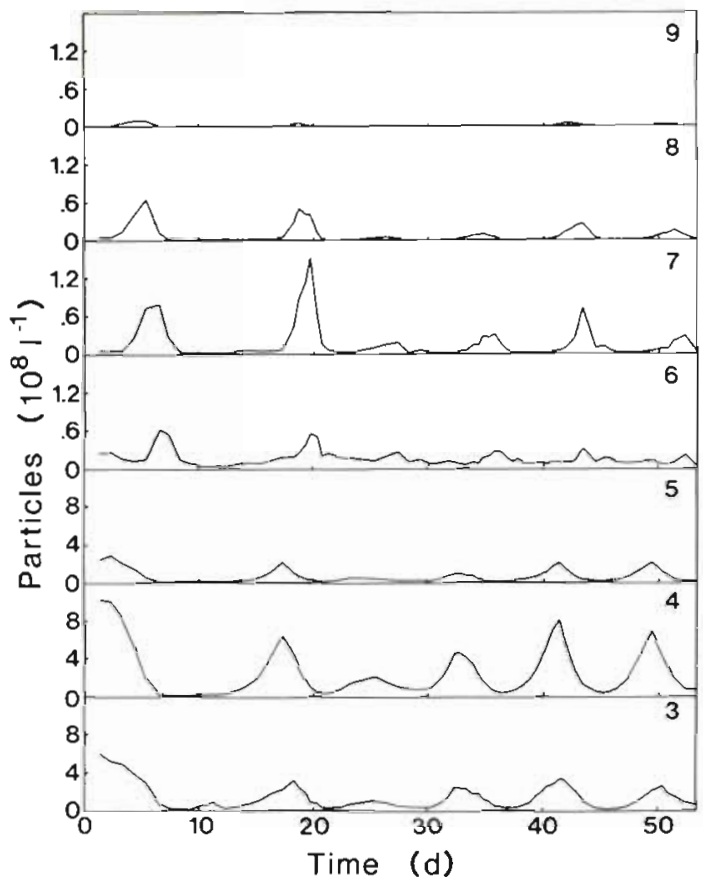

Fig. 3. Observed particle densities in Coulter-Counter channels 3 through 9 (channel indicated in top right corner) vs time

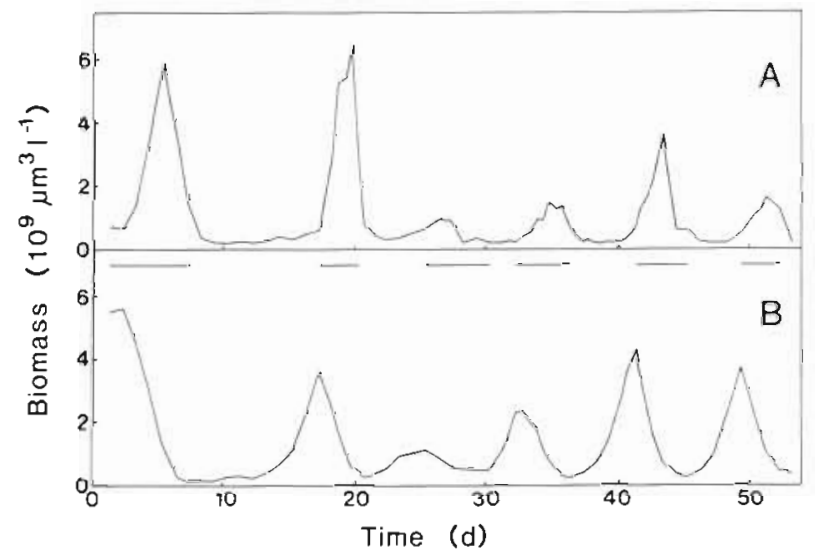

Fig. 4. Observed biomass (total cell volume) of (A) zooflagellate and (B) Micromonas pusilla vs time. Bars indicate pump on 
An initial attempt was made to fit a Lotka-Volterra type predator-prey model to the biomass time series. This model has the form:

$$
\begin{aligned}
& \frac{d P}{d t}=(r-D) P-\frac{a P B}{K+P} \\
& \frac{d B}{d t}=\frac{c P B}{K+P}-(d+D) B
\end{aligned}
$$

where $\mathrm{P}$ and $\mathrm{B}=$ prey (Micromonas pusilla) and predator (Pseudobodosp.) densities respectively; $\mathrm{D}=$ the dilution rate; $r=$ the intrinsic rate of prey biomass growth; $K=$ the half-saturation constant for ingestion; $\mathrm{a}, \mathrm{c}$, and $\mathrm{d}$ are normally interpreted as the maximum ingestion rate, the maximum assimilation rate and a constant intrinsic predator loss term, respectively. The dilution rate was either $0.75 \mathrm{~d}^{-1}$ (pump on) or 0.0 (pump off) (Fig. 4). The growth rate $r$ is assumed to be constant and equal to $0.7 \mathrm{~d}^{-1}$ based on turbidostat studies of zooflagellate-free cultures under identical light and nutrient conditions. (As described in the previous section, the pump was used to ensure that densities were low enough to prevent ammonium-limitation of growth.)

The Model (1) was implemented numerically and fit to the observations using a standard systems identification procedure described in an earlier publication (Parslow et al. 1979). Briefly, this procedure uses a Marquadt algorithm to find that set of values for the parameters $\mathrm{a}, \mathrm{K}, \mathrm{c}$, and $\mathrm{d}$ which allows the model, starting from observed initial conditions, to minimize the sum of squared deviations between predictions and observations. When driven by a prescribed time series of dilution rates $\mathrm{D}(\mathrm{t})$, as was done here, the Model (1) is dynamically unstable (Bazykin 1974): solutions starting arbitrarily close together will deviate widely after sufficient time has elapsed. It was therefore not surprising that it proved impossible to fit all 6 population cycles simultaneously. Instead, we chose to fit Model (1) to 5 subsets of the data, each consisting of the trailing edge of one peak and the entire following cycle. This forced the model to match the timing between peaks, as well as the rise and fall within individual peaks.

The Lotka-Volterra Model (1) was able to provide a good qualitative fit to each pair of biomass cycles (Fig. 5), but the parameter estimates (Table 1) showed a disconcerting amount of variation among cycles. The predicted net zooplankton growth rates $\mu_{\mathrm{B}}=\mathrm{c} \mathrm{P} /(\mathrm{K}+$ P) $-d$, calculated using the estimates in Table 1, were plotted against the phytoplankton biomass $P$, over the range of $P$ values observed in the corresponding cycles (Fig. 6). These curves together define a saturating relation, with a maximum growth rate between 1.5 and $2 \mathrm{~d}^{-1}$, a maximum mortality rate around $1 \mathrm{~d}^{-1}$, and a

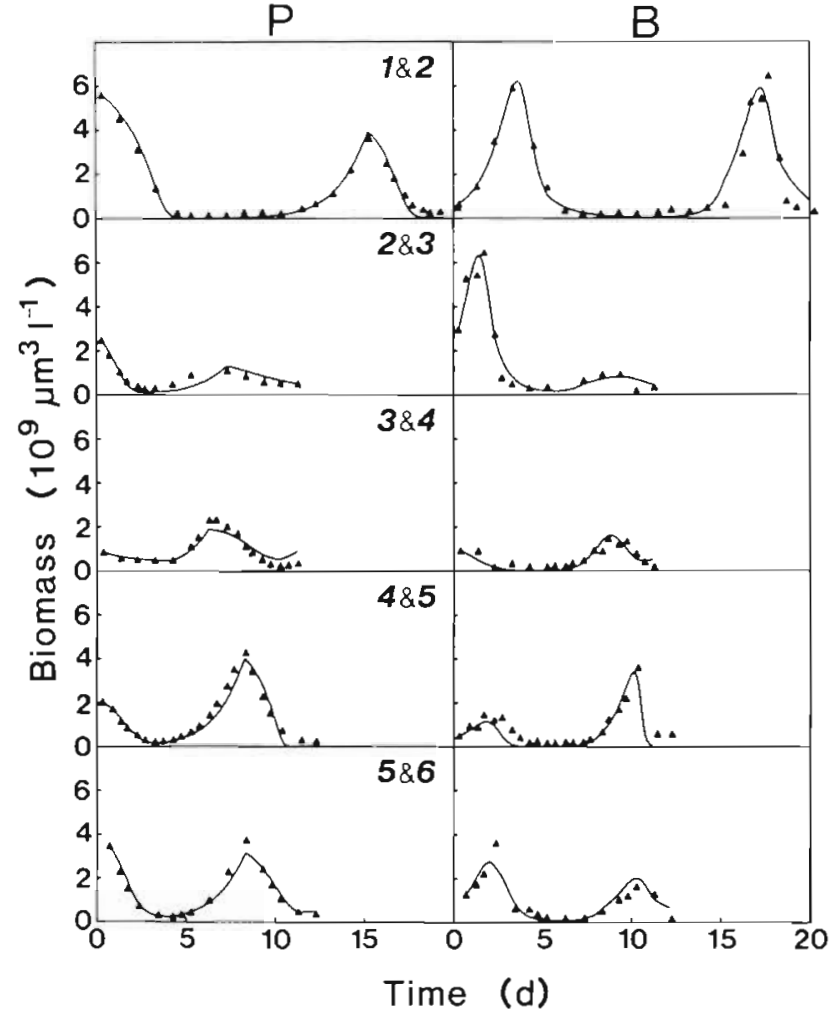

Fig. 5. Observed biomass ( $\mathbf{\Delta}$ ) and predicted biomass (solid line) for the fit by the Lotka-Volterra Model (1) to Micromonas pusilla $(\mathrm{P})$ and zooflagellate $(\mathrm{B})$. Cycles fitted are indicated at top centre

Table 1. Parameter estimates obtained by least-squares fitting the Lotka-Volterra Model (1) to the indicated biomass cycles

\begin{tabular}{llllll|}
\hline \multicolumn{1}{c}{ Cycles } & $1 \& 2$ & $2 \& 3$ & $3 \& 4$ & $4 \& 5$ & $5 \& 6$ \\
\hline $\mathrm{a}\left(\mathrm{d}^{-1}\right)$ & 0.52 & 0.40 & 1.23 & 0.91 & 0.95 \\
$\mathrm{~K}\left(10^{9} \mu \mathrm{m}^{3} \mathrm{l}^{-1}\right)$ & 0.62 & 0.63 & 3.04 & 0.16 & 0.76 \\
$\mathrm{c}\left(\mathrm{d}^{-1}\right)$ & 2.7 & 4.7 & 13.3 & 9.1 & 5.1 \\
$\mathrm{~d}\left(\mathrm{~d}^{-1}\right)$ & 0.79 & 1.98 & 2.49 & 6.86 & 2.50 \\
\hline
\end{tabular}

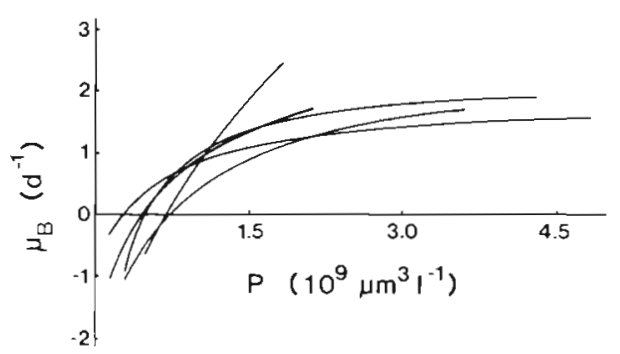

Fig. 6. Zooflagellate net growth rates vs Micromonas pusilla density according to the parameter estimates in Table 1 
compensation phytoplankton biomass of 0.3 to $0.7 \times 10^{9} \mu \mathrm{m}^{3} \mathrm{l}^{-1}$. This suggests that a consistent underlying relation exists, and that variability in the separate estimates $c, K$, and d may be due to the limitations of the estimation procedure and the data fitted. The estimated maximum specific ingestion rates (a) in Table 1 range from 0.4 to $1.23 \mathrm{~d}^{-1}$. If the fit to cycles 4 and 5 is excluded, maximum clearance rates a/K range from 0.4 to $1.25 \times 10^{-9} \mathrm{l} \mathrm{m}^{-3} \mathrm{~d}^{-1}$.

The estimates of $c$ and $d$ are too large to be sensibly interpreted in the usual way, as maximum assimilation rates and constant loss rates. If the loss rate is assumed to be variable, with a high rate when $\mathrm{P}$ is low, and a very low rate when $P$ is high, the maximum assimilation rate is equal to the maximum net growth rate, which is much more reasonable (Fig. 6). The predator equation in Model (1) can be rewritten to make this interpretation explicit:

$$
\frac{d P}{d t}=\frac{(c-d) P B}{K+P}-\frac{d B}{1+P / K}-D B .
$$

The equation now describes an assimilation rate which has a relatively low maximum value $(\mathrm{c}-\mathrm{d})$, and a loss rate $d /(l+P / K)$ which has a maximum value $d$ at $P=0$ and approaches zero at saturating values of $P$.

The variable loss rate discussed above is much more likely to be due to mortality than metabolic losses, but it is difficult to separate these loss terms using biomass data. In Fig. 3 , both zooflagellate numbers $Z(t)$ and average volume per zooflagellate $\mathrm{V}(\mathrm{t})$ are plotted against time. It is immediately clear that there are periods of high zooflagellate mortality rates associated with the decline phase of each cycle. It is also clear that

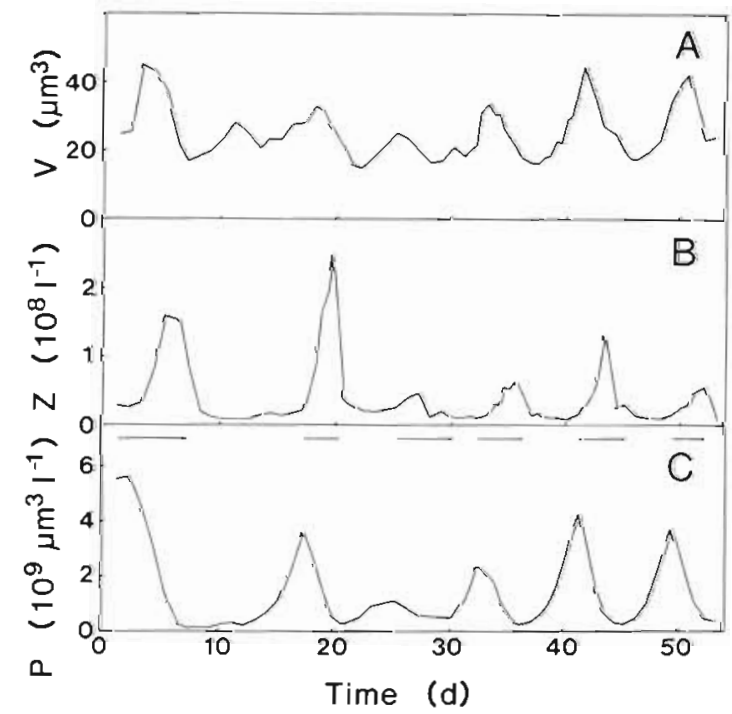

Fig. 7. Observed time series of (A) zooflagellate volume per cell, (B) zooflagellate numbers and (C) phytoplankton biomass. Bars indicate pump on there are oscillations in zooflagellate cell size associated with each cycle.

We calculated approximate cell division rates between successive observations according to the formula:

$$
\mu_{z}^{i}=\frac{\ln \left(Z_{1+1}\right)-\ln \left(Z_{1}\right)}{t_{1+1}-t_{i}}+D_{1} .
$$

When $\mu_{z}^{\mathrm{i}}$ was plotted against the corresponding average phytoplankton biomass, $\overline{\mathrm{P}}_{1}=\left(\mathrm{P}_{i}+\mathrm{P}_{i+1}\right) / 2$, no consistent relation emerged. Maximum increases in zooflagellate number appeared to lag phytoplankton biomass by several days. A tighter, though still scattered, relation was obtained between $\mu_{z}^{\mathrm{i}}$ and the corresponding average zooflagellate volume $\bar{V}_{i}=$ $\left(V_{1}+V_{i+1}\right) / 2$ (Fig. 8). The apparent linear relation between growth rate and cell volume was tested by fitting a simple dynamic model:

$$
\frac{d Z}{d T}=e\left(V(t)-V_{0}\right) Z-D Z
$$

to the time series of $Z(t)$, using the estimation technique described earlier, with the model driven by the

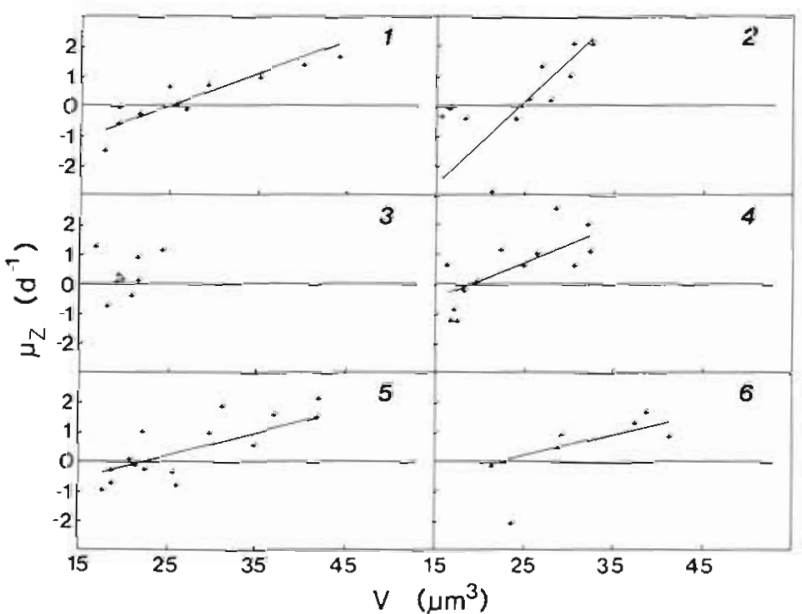

Fig. 8. Zooflagellate numerical growth rates $\mu_{2}$ vs zooflagellate volume per cell $V$, either calculated directly from successive observations as described in the text $(+)$, or predicted according to the parameter estimates in Table 2 (solid lines).

Cycle number is indicated in the top right corner

Table 2. Parameter estimates obtained by least squares fitting the linear growth Model (4) to zooplankton numbers for the indicated cycles

\begin{tabular}{lrrrrrr}
\hline \multicolumn{1}{c}{ Cycle } & 1 & 2 & 3 & 4 & 5 & 6 \\
\hline $\mathrm{e}\left(\mathrm{d}^{-1} \mu \mathrm{m}^{-3}\right)$ & 110 & .280 & - & 123 & .076 & .072 \\
$\mathrm{~V}\left(\mu \mathrm{m}^{3}\right)$ & 24.9 & 24.4 & - & 18.9 & 22.2 & 22.1 \\
\hline
\end{tabular}


observed time series $\mathrm{D}(\mathrm{t})$ and $\mathrm{V}(\mathrm{t})$. The procedure identified estimates of the parameters $e$ and $V_{0}$ which allowed a reasonable fit to the data for all cycles except cycle 3 . The estimates are given in Table 2 , and the predicted relations plotted in.Fig. 8 . The estimates of the compensation cell volume for growth, $\mathrm{V}_{0}$, all fall in a relatively narrow range from 19 to $25 \mu \mathrm{m}^{3}$. The slope e ranges from 0.08 to $0.28 \mathrm{~d}^{-1} \mu \mathrm{m}^{-3}$. It does not seem possible to blame this variability on uncertainty in the estimates: the scatter plots of $\mu_{z}^{1} v s \bar{V}_{i}$ differ markedly for different cycles (e.g. cycles 2 and 5, Fig. 8). Either the dependence of growth rate on cell volume varies over time, or cell size is serving only as a useful but inconsistent indicator of another growth-determining cell parameter.

A relation between division rate and cell size invites comparison with the Droop relation (Droop 1968), which relates growth rate to cell quota in phytoplankton. The Droop relation is hyperbolic, but tends to become linear for limiting nutrients such as carbon which make up a major fraction of the cell biomass (Goldman 1980). There has been some argument concerning the standardization of cell quotas to cell number as opposed to other biomass measures, but there are certainly other data supporting a change in flagellate cell volume with growth rate (Fenchel $1982 \mathrm{~b}, \mathrm{c})$. The Droop relation is normally applied to chemostat populations which have positive growth rates by definition; it is interesting that the relation observed in the present study apparently extends to negative net growth rates.

By analogy with cell quota models, one can write an equation for the rate of change of average cell volume in terms of the ingestation rate per cell and losses due to basal metabolism $(\mathrm{m})$ and cell division $\left(\mu_{\mathrm{c}}\right)$ :

$$
\frac{\mathrm{dV}}{\mathrm{dt}}=\frac{\mathrm{cPV}}{\mathrm{K}+\mathrm{B}}-\mathrm{mV}-\mu_{\mathrm{c}} \mathrm{V}
$$

If we assume that cell division occurs only when mortality rates are zero, then the cell division rate is given by:

$$
\mu_{c}=\mu_{+}(V)=\left\{\begin{array}{l}
e\left(V-V_{0}\right) \ldots V>V_{0} \\
0 \ldots . . V<V_{0}
\end{array}\right.
$$

Equation (5) can then be rewritten as:

$$
\frac{1}{V} \frac{d V}{d t}+\mu_{+}(V)=\frac{c P}{K+P}-m \text {. }
$$

The left-hand side can be calculated from the observations:

$$
\begin{aligned}
& \left(\frac{1}{V} \frac{d V}{d t}\right)_{i}=\frac{\ln \left(V_{i+1}\right)-\ln \left(V_{i}\right)}{t_{i+1}-t_{i}} \\
& \mu_{+}^{i}= \begin{cases}\mu_{z}^{i} & \mu_{z}^{1}>0 \\
0 & 0 / W\end{cases}
\end{aligned}
$$

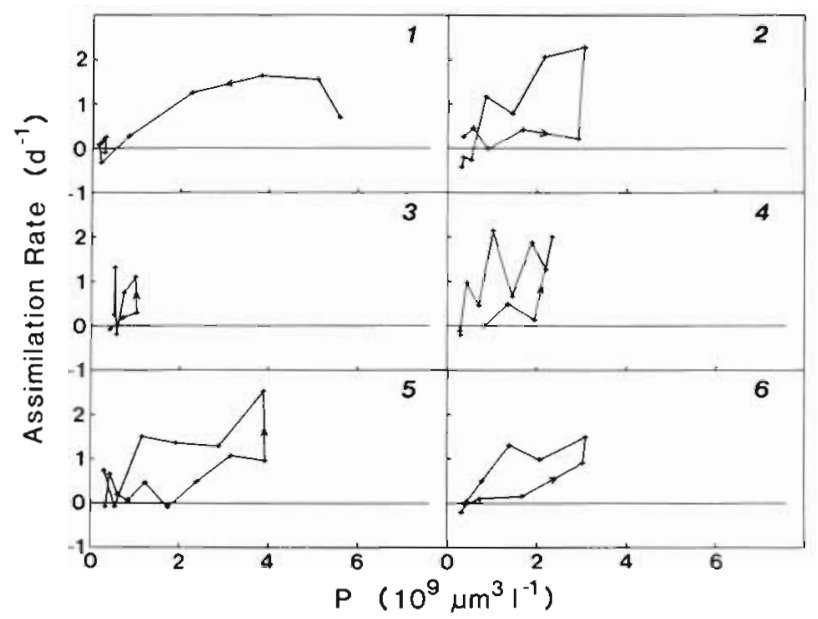

Fig. 9. Net, specific zooflagellate assimilation rate vs $\mathrm{Mi}$ cromonas pusilla biomass, calculated directly from successive observations as described in the text. Lines join points in time sequence, arrows indicating increasing time

and plotted against $\overline{\mathrm{P}}_{\mathrm{i}}$. The results (Fig. 9) do show an increase in assimilation rate with food concentration, but they also show a strong hysteresis or lag in the response of assimilation to increasing Micromonas pusilla density. This lag parallels the lag in cell size in response to food density, and we attempt to model it by making feeding depend on cell size in a non-linear way:

$$
\frac{d V}{d t}=\frac{c^{\prime} P V \gamma}{K+P}-m V-\mu_{+}(V) V
$$

When this model was driven by the observed time series $P(t)$ and fitted to $V(t)$ one cycle at a time, it yielded estimates of $\gamma$ (allometric exponential coefficient) in the range 1.8 to 2.9 . Such a strong increase in assimilation rate with $\mathrm{V}$ contrasts strongly with the usual allometric relations, which predict a $V^{0.7}$ dependence (e.g. Steele 1974). These very large values of $\gamma$ must be interpreted as evidence for changes in physiological status and activity with cell size.

Equations (5) and (6) were used as the basis for a full predator-prey model:

$$
\begin{aligned}
\frac{d P}{d t} & =(r-D) P-\frac{a^{\prime} P B}{K+P} V^{\prime} Z \\
\frac{d V}{d t} & =\frac{c^{\prime} P V}{K+P}-m V-\mu_{+}(V) V \\
\frac{d Z}{d T} & =(\mu(V)-D) Z
\end{aligned}
$$

This model, driven only by the imposed dilution rates $\mathrm{D}(\mathrm{t})$, was then fit to the full data set of Fig. 7. The number of free parameters was kept to 6 by fixing $r$ at 0.7 , as before, and fixing the exponent $\gamma$ at 2.0. The 
model was successfully fit to the data one cycle at a time; the resulting parameter estimates are given in Table 3. Again there is substantial variability among cycles, but several generalizations can be made. Estimates of the half-saturation constant $\mathrm{K}$ range from 0.6 to $3.3 \times 10^{9} \mu^{3} \mathrm{I}^{-1}$, with 4 of 6 values below $1.3 \times 10^{9}$. These values are higher than those estimated for the Lotka-Volterra biomass model (Table 1); the difference may be attributed to the dependence of ingestion on

Table 3. Parameter estimates obtained by least-squares fitting the Model ( 7 ) to the $P, V$ and $Z$ data for the indicated cycles

\begin{tabular}{|lllllll|}
\hline \multicolumn{1}{c}{ Cycle } & 1 & 2 & 3 & 4 & 5 & \multicolumn{1}{c}{6} \\
\hline $\mathrm{a}^{\prime}\left(\mathrm{d}^{-1} \mu \mathrm{m}^{-3}\right)$ & 0.013 & 0.025 & 0.118 & 0.027 & 0.056 & 0.04 \\
$\mathrm{~K}\left(10^{9} \mu \mathrm{m}^{3} \mathrm{l}^{-1}\right)$ & 0.60 & 1.26 & 3.32 & 1.30 & 2.90 & 1.03 \\
$\mathrm{c}^{\prime}\left(\mathrm{d}^{-1} \mu \mathrm{m}^{-3}\right)$ & 0.043 & 0.085 & 0.126 & 0.129 & 0.091 & 0.06 \\
$\mathrm{~m}\left(\mathrm{~d}^{-1}\right)$ & 0.09 & 0.49 & 0.26 & 0.88 & 0.27 & 0.42 \\
$\mathrm{e}\left(\mathrm{d}^{-1} \mu \mathrm{m}^{-3}\right)$ & 0.082 & 0.280 & 0.139 & 0.095 & 0.102 & 0.07 \\
$\mathrm{~V}_{0}\left(\mu \mathrm{m}^{3}\right)$ & 23.8 & 26.4 & 18.2 & 17.7 & 22.8 & 22.8 \\
Clearance & 0.20 & 0.18 & 0.32 & 0.19 & 0.17 & 0.39 \\
$\quad\left(30 \mathrm{a}^{\prime} / \mathrm{K}\right)$ & & & & & & \\
$\left(10^{-7} \mathrm{l} \mathrm{d} \mathrm{d}^{-1}\right.$ ind $\left.^{-1}\right)$ & & & & & & \\
\hline
\end{tabular}

cell size in Model ( 7 ). The cell-size dependence also complicates the interpretation of the ingestion parameters $a^{\prime}$ and $c^{\prime}$. At an intermediate cell volume of $30 \mu \mathrm{m}^{3}$, these estimates correspond to specific ingestion rates ranging from 0.4 to $3.5 \mathrm{~d}^{-1}$ and specific assimilation rates from 1.3 to $3.9 \mathrm{~d}^{-1}$. The corresponding maximum clearance rates ranged from 0.17 to $0.39 \times 10^{-7} \mathrm{l} \mathrm{d}^{-1}$ ind $^{-1}$. The estimates of the constant 'metabolic' rate $\mathrm{m}$ are generally low $\left(<0.5 \mathrm{~d}^{-1}\right)$.

A serious anomaly remains in the parameter estimates for Model (7). If metabolic and mortality losses have been effectively distinguished, it should be possible to interpret the ratio $c^{\prime} / \mathrm{a}^{\prime}$ as an assimilation efficiency $\left(\mu \mathrm{m}^{3}\right.$ zooflagellate volume produced per $\mu \mathrm{m}^{3}$ Micromonas pusilla volume grazed). But this ratio is consistently greater than 1 , ranging from 1.1 to a maximum of 4.8 . Values greater than 1 can only be reconciled with mass conservation if zooflagellates contain much less carbon per unit volume than $M$. pusilla. We will return to this point shortly after discussing the starvation response of zooflagellates.

Although the Model (7) was able to reproduce changes in $\mathrm{P}, \mathrm{V}$, and $\mathrm{Z}$ during one cycle, it had much more difficulty in reproducing 2 consecutive cycles. This appeared to be associated with the representation of the zooflagellate response to declining food levels. In reality zooflagellates continue to increase in number as food levels decline, then undergo a sharp burst of mortality, and subsequently stabilize in number, although food levels and zooflagellate cell size may remain very low for several more days. The model cannot reproduce this sharp burst of mortality; consequently the phytoplankton tend to be overgrazed. Food levels then remain very low for several days and the zooflagellate cell volume continues to decrease, resulting in an extended period of high mortality rates. Zooflagellate mortality, although it occurs late in the model, remains high for too long, and zooflagellate numbers also drop well below the observed values. The model then tends to mistime the following peak.

Attempts to resolve this problem by constructing a new model in which zooflagellate mortality depended directly on food density, as in Equation (2), were unsuccessful. We are forced to conclude that mortality cannot be adequately modelled as a simple function of zooflagellate cell size or food density. Interestingly, a previous study of the response of zooflagellates to starvation (Fenchel 1982c) reports behaviour which is remarkably similar to that which we have inferred from our analysis. In that study, zooflagellates which ran out of food were observed to undergo a rapid decrease in cell volume, a short period of high mortality rates, and then to enter an extended survival stage, with low mortality and metabolic rates. This also resulted in a lag in the response of ingestion to high food concentrations, a behaviour which could explain the hysteresis in Fig. 8. In the earlier study, TEM sections of starving zooflagellates showed an increasing proportion of the cell volume taken up by vacuoles. This may partly explain our anomalous estimates of the assimilation efficiency $c / \mathrm{a}$ '.

The burst of high mortality during the starvation period could be due to cannibalism, as Fenchel (1982c) discussed. We did attempt to fit our biomass data with a Lotka-Volterra model including cannibalism:

$$
\begin{aligned}
& \frac{d P}{d t}=r P-\frac{a P B}{K+P+a B} \\
& \frac{d B}{d t}=\frac{c P B}{K+P+\alpha B}-\frac{f^{2}}{K+P+\alpha B}-d B
\end{aligned}
$$

In this model, $\mathrm{P}$ and $\mathrm{B}$ are assumed to be competitive food resources for the zooflagellates, with the relative preference fixed by the parameter $a$. The coefficient $f$ allows for the maximum ingestion rate of zooflagellates by zooflagellates, and also allows for the net loss in biomass due to assimilation efficiencies in cannibalism. This model could not provide a good fit to the observations, for the interesting reason that, when cannibalism is significant, the Model (8) has a stable equilibrium, and trajectories become trapped near this equilibrium after one cycle. 


\section{DISCUSSION}

The data leave no doubt that the zooflagellate in the present study, tentatively identified as Pseudobodosp., is capable of phagocytizing Micromonas pusilla, of rapid growth with $M$. pusilla as the primary food source, and of rapidly reducing $M$. pusilla densities. This zooflagellate is similar in size and functional morphology to those zooflagellates which have been isolated from natural marine samples and postulated to exert an important and possibly controlling influence on heterotrophic bacteria in the oceans (Fenchel 1982d, Caron et al. 1982, Sherr et al. 1984). It now seems likely that these flagellates exert an equally important influence on populations of eukaryotic, autotrophic picoplankton such as $M$. pusilla.

This conclusion is supported by a quantitative comparison of the parameter estimates obtained in the present study with those obtained in previous studies using heterotrophic bacteria. The maximum zooflagellate growth rates obtained in the present study, ca $2 \mathrm{~d}^{-1}$, are lower than those reported by Fenchel (1982b: 3.6 to $6 \mathrm{~d}^{-1}$ at $20^{\circ} \mathrm{C}$ ), but closer to those reported by Sherr et al. (1983: 2.1 to $3.4 \mathrm{~d}^{-1}$ at 18 to $24^{\circ} \mathrm{C}$ ). The maximum clearance rates estimated here, 2 to $5 \times 10^{4}$ $\mu \mathrm{m}^{3}$ ( $\mu \mathrm{m}^{3}$ zooflagellate $)^{-1} \mathrm{~h}^{-1}$, are again at the low end of Fenchel's range $\left(5 \times 10^{4}\right.$ to $10^{6}$ in these units). However, the maximum clearance rates per individual $(1.2$ to $2.4 \times 10^{8} \mathrm{l}_{\text {ind }}^{-1} \mathrm{~d}^{-1}$ ) reported by Sherr et al. (1983) compare very well with the estimates given in Table 3 . (The food organism in the present study is highly motile, and one might expect this to increase encounter rates and clearance rates. However, this may be offset by the relatively low capture success rate observed under the microscope.) Finally, the half-saturation constants for growth reported by Fenchel

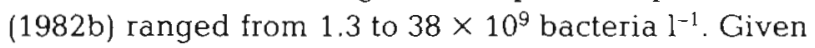
his reported average bacterial cell colume of $0.6 \mu \mathrm{m}^{3}$, this corresponds to 1 to $23 \times 10^{9} \mu \mathrm{m}^{3} \mathrm{l}^{-1}$. The estimates obtained in the present study (Table 1 \& 3; Fig. 3) lie within, and towards the lower end of, this range.

In this study, we attempted to estimate population parameters by deliberately perturbing the experimental system and using systems identification procedures to fit nonlinear dynamic models to the resulting time series. This has not yielded the clear-cut results others have obtained by studying steady-state chemostat cultures of ciliates (Hamilton \& Preslan 1970, Droop \& Scott 1982) or dilute batch cultures of zooflagellates in exponential phase (Fenchel 1982b). The difficulties encountered in the present study may have been partly due to deficiencies in the data collected or the estimation procedures used. However, our analysis suggests that the response of zooflagellates to fluctuating food densities is intrinsically more complicated than obser- vations of steady-state growth would suggest. These complexities include both time lags in the response of ingestion to increasing food density, and a complex response of cell size, physiological state, and death rate to decreasing food density. Similar complexities have been encountered in studies of the transient response of autotrophs to changes in the limiting nutrient supply rate (Cunningham \& Maas 1978, Cunningham \& Nisbet 1980). The present observations, and those of Fenchel (1982c), suggest that considerable caution should be exercised in the use of steady-state chemostat results to predict or model zooflagellate populations in the field. As others have pointed out, zooflagellates feeding on heterotrophic bacteria may be faced with an essentially heterogeneous resource, especially those specializing on bacteria associated with particulate detritus (e.g. Caron et al. 1982). Even those feeding on free-living bacteria (Azam et al. 1983), or picoautotrophs, may face temporal changes on time scales of days (Fenchel 1982d). In either case, simple Lotka-Volterra models, which seem reasonable based on steady-state laboratory results, may yield a misleading picture of the qualitative stability properties, and the quantitative time evolution, of zooflagellate-prey interactions.

\section{LITERATURE CITED}

Azam, F., Fenchel, T., Field, J. G., Gray, J. S., Meyer-Keil L. A., Thingstad, F. (1983). The ecological role of watercolumn microbes in the sea. Mar. Ecol. Prog. Ser. 10: $257-263$

Bazykin, A. D. (1974). Volterra's system and the MichaelisMenton equation. In: Ratner, V. A. (ed.) Problems in mathematical genetics. U.S.S.R. Acad. Sci. Norosibirsh., p. 103-142

Caron, D. A., Davis, P. G., Madin, L. P., Sieburth, J. McN. (1982). Heterotrophic bacteria and bacterivorous protozoa in oceanic macroaggregates. Science 218: 795-797

Cunningham, A., Maas, P. (1978). Time lag and nutrient storage effects in the transient growth response of Chlamydomonas reinhardii in nitrogen-limited batch and continuous culture. J. gen. Microbiol. 104: 227-231

Cunningham, A., Nisbet, R. M. (1980). Time lag and cooperativity in the transient growth dynamics of microalgae. J. theor. Biol. 84: 189-203

Davis, P. W., Sieburth, J. McN. (1982). Differentiation of the phototrophic and heterotrophic nanoplankton populations in marine waters by epifluorescence microscopy. Annls Inst. océanogr., Paris 58: 249-260

Davis, P. W. Sieburth, J. McN. (1984). Estuarine and oceanic microflagellate predation of actively growing bacteria: estimation by frequency of dividing-divided bacteria. Mar. Ecol. Prog. Ser. 19: 237-246

Droop, M. R. (1968). Vitamin $B_{12}$ and marine ecology. IV. The kinetics of uptake, growth and inhibition in Monochrysis Iutheri. J. mar. biol. Ass. U. K. 48: 689-733

Droop, M. R., Scott, J. M. (1982). A steady-state approach to some microplankton problems. Annls Inst. océanogr. Paris 58: 47-54 
Fenchel, T. (1982a). Ecology of heterotrophic microflagellates. I. Some important forms and their functional morphology. Mar. Ecol. Prog. Ser. 8: 211-223

Fenchel, T. (1982b). Ecology of heterotrophic microflagellates. II. Bioenergetics and growth. Mar. Ecol. Prog. Ser. 8; 225-231

Fenchel, T. (1982c). Ecology of heterotrophic microflagellates. III. Adaptations to heterogeneous environments. Mar. Ecol. Prog. Ser. 9: 25-33

Fenchel, T. (1982d). Ecology of heterotrophic microflagellates. IV. Quantitative occurrence and importance as bacterial consumers. Mar. Ecol. Prog. Ser. 9: 35-42

Goldman, J. C. (1980). Physiological processes, nutrient availability, and the concept of relative growth rate in marine phytoplankton ecology. In: Falkowski, P. G. (ed.) Primary productivity in the sea. Plenum Press, New York, p. 179-194

Griessmann, K. (1914). Über marine Flagellaten. Arch. Protistenk. 32: 1-78

Hamilton, R. D., Preslan, J. E. (1970). Observations on the continuous culture of a planktonic phagotrophic protozoan. J. exp. mar. Biol. Ecol. 5: 94-104

Harrison, P. J., Waters, R. E., Taylor, F. J. R. (1980). A broad spectrum artificial seawater medium for coastal and open ocean phytoplankton. J. Phycol. 16: 28-35

Johnson, P. W., Sieburth, J. McN. (1979). Chroococcoid cyanobacteria in the sea: a ubiquitous and diverse phototrophic biomass. Limnol. Oceanogr. 24: 928-935

Johnson, P. W., Sieburth, J. McN. (1982). In-situ morphology and occurrence of eucaryotic photoautotrophs of bacterial size in the picoplankton of estuarine and oceanic waters. J. Phycol. 18: 318-327
Johnson, P. W., Xu, H.-S., Sieburth, J. McN. (1982). The utilization of chroococcoid cyanobacteria by marine protozooplankters but not by calanoid copepods. Annls Inst. océanogr., Paris 58: 297-308

Parslow, J. S., Harrison, P. J., Thompson, P. A. (1984). Development of rapid ammonium uptake during starvation of batch and chemostat cultures of a marine diatom Thalassiosira pseudonana. Mar. Biol. 83: 43-50

Parslow, J., Sonntag, N. C., Mathews, J. B. L. (1979). Technique of systems identification applied to estimating copepod parameters. J. Plankton Res. 1: 137-151

Sherr, E. B., Sherr, B. F. (1983). Double-staining epifluorescence techniques to assess frequency of dividing cells and bactivory in natural populations of heterotrophic microprotozoa. Appl. environ. Microbiol. 46: 1388-1393

Sherr, B. F., Sherr, E. B., Bermann, T. (1983). Grazing, growth and ammonium excretion rates of a heterotrophic microflagellate fed with four species of bacteria. Appl. environ. Microbiol. 45: 1196-1201

Sherr, B. F., Sherr, E. B., Newell, S. Y. (1984). Abundance and productivity of heterotrophic nanoplankton in Georgia coastal waters. J. Plankton Res. 6: 195-202

Sieburth, J. McN., Davis P. G. (1982). The role of heterotrophic nanoplankton in the grazing and nurturing of planktonic bacteria in the Sargasso and Caribbean seas. Annls Inst. océanogr., Paris 58: 285-296

Sorokin, Yu. I. (1981). Microheterotrophic organisms in marine ecosystems. In: Longhurst, A. R. (ed.) Analysis of marine ecosystems. Academic Press, London, p. 293-342

Steele, J. H. (1974). The structure of marine ecosystems. Harvard University Press, Cambridge 